\title{
High-efficiency tooth bleaching using non- thermal atmospheric pressure plasma with low concentration of hydrogen peroxide
}

\author{
Seoul Hee NAM1, Hyun Woo LEE², Soo Hyun CHO ${ }^{3}$, Jae Koo LEE², Young Chan JEON, Gyoo Cheon KIM \\ 1- MSc, PhD student, Department of Oral Anatomy, School of Dentistry, Pusan National University, Yangsan, Republic of Korea. \\ 2- PhD, Department of Electronic and Electrical Engineering, Pohang University of Science and Technology, Pohang, Republic of Korea. \\ 3- DDS, MSc, Department of Oral Anatomy, School of Dentistry, Pusan National University, Yangsan, Republic of Korea. \\ 4- DDS, PhD, Department of Prosthetic Dentistry, School of Dentistry, Pusan National University, Yangsan, Republic of Korea. \\ 5- PhD, Department of Oral Anatomy, School of Dentistry, Pusan National University, Yangsan, Republic of Korea.
}

Corresponding address: Gyoo Cheon Kim - Department of Oral Anatomy, School of Dentistry, Pusan National University - Beomeo-ri - Mulgeum-eup - Yangsansi - Gyeongsangnam - 626-870 - Republic of Korea - Phone: 82-10-5251-8214 - 82-51-510-8243 - Fax: 82-51-510-8241 - e-mail: ki91000m@pusan.ac.kr

Received: January 8, 2013 - Modification: March 29, 2013 - Accepted: May 5, 2013

\section{ABSTRACT}

ight-activated tooth bleaching with a high hydrogen peroxide $\left(\mathrm{HP} ; \mathrm{H}_{2} \mathrm{O}_{2}\right)$ concentration Lhas risks and the actual role of the light source is doubtful. The use of conventional light might result in an increase in the temperature and cause thermal damage to the health of the tooth tissue. Objective: This study investigated the efficacy of tooth bleaching using non-thermal atmospheric pressure plasma (NAPP) with 15\% carbamide peroxide (CP; $\mathrm{CH}_{6} \mathrm{~N}_{2} \mathrm{O}_{3}$ ) including $5.4 \% \mathrm{HP}$, as compared with conventional light sources. Material and Methods: Forty human teeth were randomly divided into four groups: Group I (CP+NAPP), Group II (CP+plasma arc lamp; PAC), Group III (CP+diode laser), and Group IV (CP alone). Color changes $(\Delta E)$ of the tooth and tooth surface temperatures were measured. Data were evaluated by one-way analysis of variance (ANOVA) and post-hoc Tukey's tests. Results: Group I showed the highest bleaching efficacy, with a $\Delta E$ value of 1.92-, 2.61 and 2.97-fold greater than those of Groups II, III and IV, respectively $(\mathrm{P}<0.05)$. The tooth surface temperature was maintained around $37^{\circ} \mathrm{C}$ in Group I, but it reached $43^{\circ} \mathrm{C}$ in Groups II and III. Conclusions: The NAPP has a greater capability for effective tooth bleaching than conventional light sources with a low concentration of HP without causing thermal damage. Tooth bleaching using NAPP can become a major technique for in-office bleaching in the near future.

Key words: Tooth bleaching. Plasma gases. Hydrogen peroxide. Temperature.

\section{INTRODUCTION}

Modern tooth bleaching agents are based primarily on hydrogen peroxide $\left(\mathrm{HP} ; \mathrm{H}_{2} \mathrm{O}_{2}\right)$ and carbamide peroxide $\left(\mathrm{CP} ; \mathrm{CH}_{6} \mathrm{~N}_{2} \mathrm{O}_{3}\right)^{18}$. Both bleaching agents effectively remove chromogens deposited on the enamel and dentin of teeth, thereby whitening the tooth ${ }^{1}$. High-concentration peroxides are used for in-office bleaching, and low concentrations are used for at-home bleaching. In-office bleaching is generally performed using high concentrations (35-50\%) of HP-containing gel in combination with light sources ${ }^{28}$. However, high concentrations of HP can cause problems, such as external cervical root resorption, tooth sensitivity, alteration of the enamel surfaces, and pulp damage $\mathrm{e}^{4,22}$. On the other hand, at-home bleaching is performed using low concentrations of CP (usually containing 2-10\% HP), which are applied for several hours per day for several weeks ${ }^{8}$. Unlike in-office bleaching, at-home bleaching does not guarantee immediate results. Therefore, in-office bleaching is quicker and more efficient.

The theoretical advantage of light sources is that they heat the HP, thereby increasing the rate of decomposition of oxygen into free radicals and increasing its bleaching effect ${ }^{30}$. The halogen curing light, plasma arc lamp (PAC; bleaching mode), 
metal halide lamp, light emitting diode, and laser are widely-used light sources that accelerate the in-office tooth bleaching procedure ${ }^{3}$. However, the actual role of the light source in tooth bleaching remains a source of controversy.

Some reports claim that the use of light sources increases the efficacy of bleaching treatments ${ }^{21,27}$; conversely, other articles have reported that light sources have no clinically significant effects on tooth bleaching ${ }^{9,24}$. Furthermore, the light energy may increase the tooth temperature, potentially leading to irreversible thermal damage of the pulp tissue ${ }^{15}$. Therefore, an effective, non-thermal light source is desired for successful and safe tooth bleaching.

The fields of biology and medicine, including dental medicine, have employed plasma, the fourth state of matter. Since 2000, non-thermal atmospheric pressure plasma (NAPP) has attracted great interest and has been widely used in biomedical applications, such as sterilization, treatment of eukaryotic cells, wound healing, blood coagulation, and dental applications $7,10,13,16,20$. NAPP has been shown to have a strong tooth bleaching effect $^{16,17,25}$. We supposed that if the NAPP is able to achieve the effects of in-office bleaching using the low CP concentrations of at-home bleaching, the NAPP could become an important energy source for tooth bleaching. This in vitro study examined the bleaching efficacy of the NAPP, PAC, and diode laser with a low concentration of $15 \%$ CP containing $5.4 \%$ $\mathrm{HP}$ by analyzing the color change and temperature increase of the tooth surface after treatment.

\section{MATERIAL AND METHODS}

\section{Plasma device}

Figure 1 illustrates the process for external bleaching using the NAPP jet. The hand held NAPP jet is driven by a low frequency $(20 \mathrm{kHz})$ high voltage source (half the peak-to-peak amplitude $=5$ $\mathrm{kV}$ ). We used helium gas with a flow rate of $2 \mathrm{~L} \cdot \mathrm{min}^{-1}$ for a safe and stable operation of the NAPP jet. A detailed description and analysis of the electrical and physical features of the NAPP jet are beyond the scope of this paper, but we have reported this previously ${ }^{16,17}$.

\section{Tooth preparation and selection}

We used forty extracted human molar teeth with intact crowns in this experiment after receiving approval from the research ethics committee of the Pusan National University Yangsan Hospital, Yangsan, Korea (approval \#04-2012-012). All teeth were stored in a $0.4 \%$ sodium azide solution to prevent bacterial growth. Before the bleaching procedure, we cleaned the teeth using scalers to remove the calculus and soft tissue remnants. We then polished them with water/pumice slurry in dental prophylactic cups and examined them under a stereomicroscope (40× magnification, SZ-CTV, Olympus, Tokyo, Japan) and selected teeth with no signs of fracture, caries, lesions, or surface defects. We removed the root portions of the teeth horizontally using a water-cooled lowspeed diamond saw (Struers Minitom, Struers A/S, Copenhagen, Denmark). Each crown was vertically bisected, and the cut surfaces of the teeth were waterproofed with two layers of nail varnish. All the teeth were then stored in artificial saliva (Taliva, Hanlim, Seoul, Korea) before tooth bleaching.

\section{Tooth bleaching procedure}

The crowns of the human teeth were subjected to $142 \mu \mathrm{l} 15 \% \mathrm{CP}$ gel (Kool white 15\%, Pac-dent International, Walnut, CA, USA), activated by three different sources: the NAPP, PAC, and diode laser. We followed the protocols for applying the light sources as per the manufacturers' instructions (Figure 2). The four groups differed in light sources, treatment durations, and application devices. The forty teeth were randomly divided into four groups $(n=10)$ and were treated with NAPP, PAC, diode laser, or $\mathrm{CP}$ alone (control). Before tooth bleaching, the surface of each tooth was photographed using a digital imaging system under a stereomicroscope (10× magnification).

In all groups, we covered the buccal surfaces with a uniform layer (approximately $1 \mathrm{~mm}$ thick) of $15 \% \mathrm{CP}$ gel containing $5.4 \%$ HP every $10 \mathrm{~min}$, according to the manufacturer's guidelines. In Group I, we applied 15\% CP gel and NAPP (500-750 $\mathrm{nm}$, helium lines) for $20 \mathrm{~min}$. The tip of the NAPP device was kept at a distance of $1 \mathrm{~cm}$ from the tooth surface. After $10 \mathrm{~min}$, the teeth were carefully washed with distilled water to remove the CP gel and were dried with absorption paper. All teeth were photographed under a stereomicroscope. We repeated the procedure one more time, so that the total treatment was 20 min. Group II was treated
A

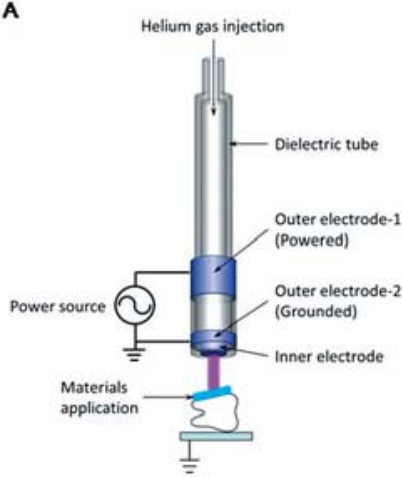

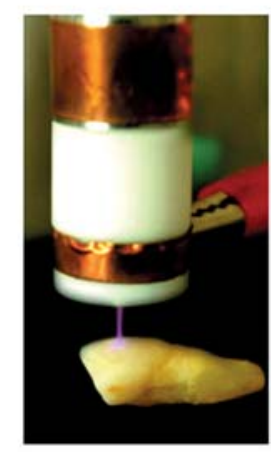

Figure 1- The process of light-activated tooth bleaching using non-thermal atmospheric pressure plasma. (A) Schematic of the plasma device and of the process and (B) photograph of the tooth bleaching experiment 


\begin{tabular}{|c|c|c|c|}
\hline $\begin{array}{c}\text { Light unit } \\
\text { (Brand) }\end{array}$ & Manufacturer & $\begin{array}{c}\text { Light activation } \\
\text { source }\end{array}$ & $\begin{array}{c}\text { Application } \\
\text { time (min) }\end{array}$ \\
\hline Curing \& Whitening BC 330 & B\&B Systems, South Korea & $\begin{array}{c}\text { Plasma Xenon Arc Lamp } \\
(380-520 \mathrm{~nm} \pm 10 \mathrm{~nm})\end{array}$ & 20 \\
\hline Vision MDL-10 & $\begin{array}{c}\text { Vision Lasertechnik GmbH, } \\
\text { Rodenberg, Germany }\end{array}$ & Diode laser (980 $\pm 10 \mathrm{~nm})$ & 20 \\
\hline
\end{tabular}

Figure 2- Light sources employed in this study

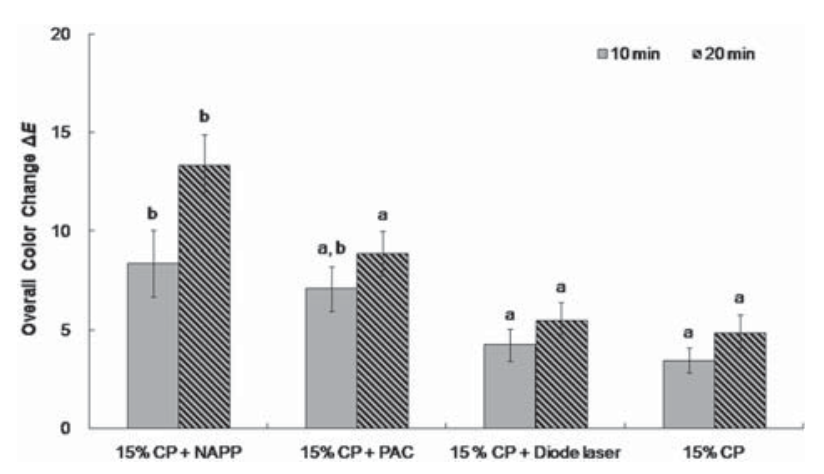

Figure 3- The tooth bleaching effects of three different light sources and the control group. Each $\Delta \mathrm{E}$ value was measured at $10 \mathrm{~min}$ and $20 \mathrm{~min}$. Statistical analysis of $\Delta \mathrm{E}$ was performed using one-way ANOVA and Tukey's tests $(a, b)$ Different letters indicate statistically significant differences $(P<0.05)$

in the same manner as Group I, but the activation was performed with a PAC (380-520 $10 \mathrm{~nm}, 30$ $\mathrm{mW} / \mathrm{cm}^{2} \pm 20 \%$, Curing \& Whitening BC 330, B\&B Systems, Seoul, Korea) for 20 min. Group III was treated with $15 \% \mathrm{CP}$ gel using a diode laser (Vision MDL-10, Vision Lasertechnik GmbH, Rodenberg, Germany) with an emission wavelength of $980 \pm 10$ $\mathrm{nm}$ in a continuous wave mode, using a fiber optic delivery system $350 \mu \mathrm{m}$ in diameter and an output of $0.5 \mathrm{~W}$ for $20 \mathrm{~min}$. The other procedures were the same as those for Group I. Group IV (control) was treated with $15 \%$ CP gel without a light source for $20 \mathrm{~min}$.

\section{Analysis of the bleaching efficacy}

We photographed all teeth in the four groups before, during (10 $\mathrm{min})$, and after the treatment (20 min). To make determinations as accurately as possible, all measurements were obtained under standard conditions: $10 \times$ magnification, black background, blackout curtains, and exposure time ( $90.0 \mathrm{~ms}$ ) in the same room. The images were loaded onto a computer through the Image-Pro Plus 5.1 software (Media Cybernetics Inc, Bethesda, MD, USA). Color changes were evaluated with Adobe Photoshop CS2 (Adobe Systems Inc, San Jose, CA, USA). For each tooth, values were expressed according to the Commission Internationale de L'Eclairage Lab (CIELAB) Color System ${ }^{29}$. The
CIELAB system uses three parameters, $L^{*}, a^{*}$, and $b^{*}$, where $L^{*}$ indicates the brightness, and $a *$ and $b^{*}$ describe the amount of green-red and blue-yellow, respectively, in the color space of the tooth. We calculated the value of the color changes $(\Delta E)$ of the tooth according to the following formula:

$$
\Delta E=\sqrt{\left(\Delta L^{*}\right)^{2}+\left(\Delta a^{*}\right)^{2}+\left(\Delta b^{*}\right)^{2}}
$$

\section{Measurement of tooth temperature}

We measured the temperature increase in each tooth independently from the tooth bleaching experiments for each of the three light sources using a fiber optic temperature measurement system (FTI-10 fiber optic signal conditioner, FOT-L-SD fiber optic temperature sensor; FISO Technologies Inc, Québec, Canada). The fiber optic temperature sensor was placed in contact with the buccal surface, and the tooth was properly fixed. During the measurement, we had positioned the light source perpendicular to the buccal surface at a distance of $1 \mathrm{~cm}$ for $30 \mathrm{~min}$ and had performed three applications of each light source on each tooth at room temperature $\left(25^{\circ} \mathrm{C}\right)$, and at $55 \%$ humidity levels.

\section{Statistical analysis}

Statistical analysis was performed using a computerized program in SPSS $15.0^{\circledR}$ (SPSS Inc, Chicago, IL, USA). All light-activated bleaching effects and color changes for each group were analyzed by one-way analysis of variance (ANOVA) and a post-hoc Tukey's test. $\mathrm{P}<0.05$ represented statistical significance.

\section{RESULTS}

\section{Effects of tooth bleaching}

Figure 3 shows the tooth bleaching effects in the four groups. After the teeth were coated with $15 \%$ $\mathrm{CP}$, they were treated with each light source for the indicated times. While the bleaching effects from all of the light sources were time dependent, the NAPP was the most effective for bleaching. The average $\triangle E \pm$ standard deviations (SD) were $9.34 \pm 1.16$ and $14.41 \pm 1.53,6.54 \pm 1.05$ and $7.53 \pm 0.43,4.24 \pm 0.81$ and $5.52 \pm 0.87$, and $3.46 \pm 0.65$ and $4.86 \pm 0.93$ after 10 min and 20 min treatment with NAPP, PAC, diode laser, and without a light source, respectively. 
Table1- The mean $\triangle E \pm S D$ (standard deviation) after tooth bleaching using different light sources

\begin{tabular}{|c|c|c|c|c|}
\hline $\begin{array}{c}\text { Application } \\
\text { time }\end{array}$ & Mean $\Delta E \pm S D$ & Class & $\mathbf{P}$ & $\begin{array}{c}\text { ANOVA } \\
\text { P-values }\end{array}$ \\
\hline \multirow[t]{4}{*}{$10 \min$} & $15 \% \mathrm{CP}+\mathrm{NAPP}(9.34 \pm 1.16)$ & $\begin{array}{l}15 \% \mathrm{CP}+\mathrm{PAC} \\
15 \% \mathrm{CP}+\text { Diode laser } \\
15 \% \mathrm{CP}\end{array}$ & $\begin{array}{c}0.112 \\
0.001^{*} \\
0.002^{*}\end{array}$ & \multirow{4}{*}{$0.000^{*}$} \\
\hline & $15 \% \mathrm{CP}+\mathrm{PAC}(6.54 \pm 1.05)$ & $\begin{array}{l}15 \% \mathrm{CP}+\text { NAPP } \\
15 \% \mathrm{CP}+\text { Diode laser } \\
15 \% \mathrm{CP}\end{array}$ & $\begin{array}{l}0.112 \\
0.190 \\
0.163\end{array}$ & \\
\hline & $15 \%$ CP + Diode laser $(4.24 \pm 0.81)$ & $\begin{array}{l}15 \% \mathrm{CP}+\mathrm{NAPP} \\
15 \% \mathrm{CP}+\mathrm{PAC} \\
15 \% \mathrm{CP}\end{array}$ & $\begin{array}{l}0.001^{*} \\
0.190 \\
0.963\end{array}$ & \\
\hline & $15 \%$ CP $(3.46 \pm 0.65)$ & $\begin{array}{l}15 \% \text { CP + NAPP } \\
15 \% \text { CP + PAC } \\
15 \% \text { CP + Diode laser }\end{array}$ & $\begin{array}{l}0.002^{*} \\
0.163 \\
0.963\end{array}$ & \\
\hline \multirow[t]{4}{*}{$20 \mathrm{~min}$} & $15 \%$ CP + NAPP $(14.41 \pm 1.53)$ & $\begin{array}{l}15 \% \mathrm{CP}+\mathrm{PAC} \\
15 \% \mathrm{CP}+\text { Diode laser } \\
15 \% \mathrm{CP}\end{array}$ & $\begin{array}{l}0.001^{*} \\
0.000^{*} \\
0.000^{*}\end{array}$ & \multirow{4}{*}{$0.000^{*}$} \\
\hline & $15 \% \mathrm{CP}+\mathrm{PAC}(7.53 \pm 0.43)$ & $\begin{array}{l}15 \% \mathrm{CP}+\text { NAPP } \\
15 \% \mathrm{CP}+\text { Diode laser } \\
15 \% \mathrm{CP}\end{array}$ & $\begin{array}{l}0.001^{*} \\
0.073\end{array}$ & \\
\hline & $15 \%$ CP + Diode laser $(5.52 \pm 0.87)$ & $\begin{array}{l}15 \% \mathrm{CP}+\text { NAPP } \\
15 \% \mathrm{CP}+\mathrm{PAC} \\
15 \% \mathrm{CP}\end{array}$ & $\begin{array}{l}0.000^{*} \\
0.073 \\
0.967\end{array}$ & \\
\hline & $15 \%$ CP $(4.86 \pm 0.93)$ & $\begin{array}{l}15 \% \text { CP + NAPP } \\
15 \% \text { CP + PAC } \\
15 \% \text { CP + Diode laser }\end{array}$ & $\begin{array}{l}0.000 * \\
0.342 \\
0.967\end{array}$ & \\
\hline
\end{tabular}

* Statistically significant difference among the tooth bleaching groups by one-way ANOVA and Tukey's test $(P<0.05)$ $(\mathrm{CP}=$ carbamide peroxide; NAPP=nonthermal atmospheric pressure plasma; $\mathrm{PAC}=$ plasma arc lamp)

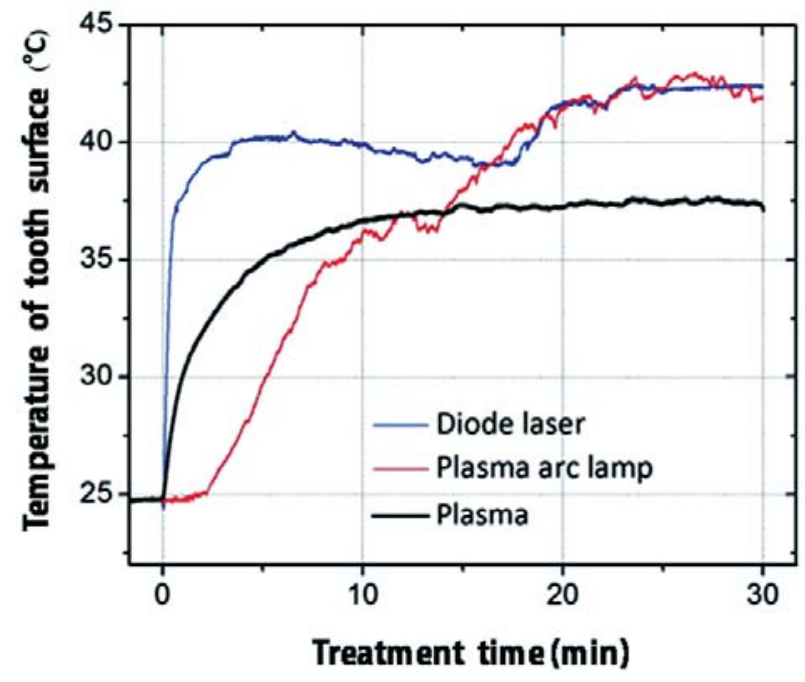

Figure 4- The temperature measurement during tooth bleaching using different light sources. During treatment with light sources, the temperature was measured at 10 , 20 , and $30 \mathrm{~min}$
The $\Delta E$ value of Group I, which was treated with NAPP, was statistically higher than that of any of the other groups $(P<0.05)$. The NAPP improved the bleaching efficacy by factors of 1.43 and $1.92,2.20$ and 2.61, and 2.70 and 2.97 compared to the PAC, diode laser, and CP alone, respectively, after $10 \mathrm{~min}$ and $20 \mathrm{~min}$. However, Table 1 demonstrates that there were no statistical differences between the other groups (II, III, and IV) $(P>0.05)$.

\section{Temperature measurement}

The temperature increase induced by the three light sources is shown in Figure 4. The PAC and diode laser increased the temperature of the buccal surface of the tooth to a greater extent than the NAPP. The temperature of a tooth treated with the NAPP stabilized near $37^{\circ} \mathrm{C}$ after $10 \mathrm{~min}$ of operation, and this state was continuously maintained throughout the treatment duration. In contrast, the PAC and diode laser increased the tooth temperature to $43^{\circ} \mathrm{C}$ and $42.5^{\circ} \mathrm{C}$, respectively, after 20 min. 


\section{DISCUSSION}

Current tooth bleaching procedures have several drawbacks: (1) at-home bleaching using low concentrations of HP is relatively safe for tissues but requires a long time for satisfactory results due to its weak effects; (2) in-office bleaching has a stronger effect but has risks due to the high HP concentration, and (3) the efficacy of light sources used in tooth bleaching is doubtful. Therefore, it would be ideal to utilize a light source that can enhance the efficacy of bleaching gels with low HP concentrations. If such a light source could produce effects similar to those of in-office bleaching, the three major problems could be simultaneously solved.

Various light sources are being used to increase the bleaching effect and shorten the duration of tooth bleaching ${ }^{12}$. Among them, the PAC and diode laser have been widely used in dental clinics ${ }^{3}$. Because the PAC has a high broadband emission (400-580 $\mathrm{nm}$ ) and high-energy intensity, it has been used for tooth bleaching as well as resin curing ${ }^{26}$. Nakamura, et al. ${ }^{23}$ (2001) and Kashima-Tanaka, et al. ${ }^{14}$ (2003) reported that the PAC significantly changed the tooth color, whereas Hein, et al. ${ }^{9}$ (2003) and Lima, et al. ${ }^{19}$ (2009) demonstrated that the PAC did not effectively activate the bleaching gels. Because laser tooth bleaching began about 15 years ago, many kinds of laser devices have been used for tooth bleaching ${ }^{2,11}$. Laser irradiation is known to reduce the total treatment time and has the virtue of mitigating tooth sensitivity accompanied by inoffice bleaching. However, the bleaching effects caused by laser irradiation remain in question.

This study demonstrated that the bleaching effect of the NAPP was superior to those of the other two light sources. The $\Delta E$ value achieved with the NAPP was significantly higher than those achieved with the PAC and diode laser. The NAPP group had statistically significant differences from all the other groups. When the PAC and diode laser were used to irradiate for $20 \mathrm{~min}$ in this study, the $\Delta E$ values increased more than that of the control group, but there were no statistically significant differences. When we irradiated with the diode laser for $20 \mathrm{~min}$, the $\Delta E$ value was only slightly different from that of the control group. These results demonstrate that neither light source is appropriate for accelerating the effects of $15 \% \mathrm{CP}$.

The $15 \%$ CP used in this study includes only $5.4 \%$ HP. Considering that $30-50 \%$ HP is generally used for in-office bleaching, the reason that the PAC and diode laser did not show bleaching effects in this study could be due to the low concentration of HP. However, NAPP irradiation significantly increased the $\Delta E$ value after $10 \mathrm{~min}$, and after $20 \mathrm{~min}$, the $\Delta E$ value was much higher than those of the other two light sources. This demonstrates that, with a low concentration of $\mathrm{CP}$, the NAPP has a stronger bleaching effect than the other two light sources. The $\Delta E$ value of Group I was approximately $1.54^{16}$ and 2.03 times higher than those after treatment with $30 \% \mathrm{HP}$ alone for $10 \mathrm{~min}$ and $20 \mathrm{~min}$, respectively (data not shown). Because the NAPP produces large amounts of energetic ions, charged particles, and free radicals, these might interact with the HP, thereby synergistically enhancing the bleaching effect.

Since human tissues are sensitive to heat, many studies have investigated thermal damage to the pulp of teeth induced by light sources. Temperatures in excess of $42.5^{\circ} \mathrm{C}$ may induce degradation of the pulp tissues ${ }^{6}$. Similar to previous reports ${ }^{2,5}$, this study found that the PAC and diode laser increased the temperature of the tooth surface to approximately $43^{\circ} \mathrm{C}$ and $42.5^{\circ} \mathrm{C}$, respectively, after $20 \mathrm{~min}$. The NAPP, however, took about $10 \mathrm{~min}$ to reach a steady-state temperature, and thereafter the tooth surface temperature was maintained around $37^{\circ} \mathrm{C}$. The fact that the temperature of the NAPP treatment is similar to the human body temperature means that a patient could not feel a sense of pain from cold or heat. Furthermore, it does not induce thermal damage in the tooth pulp or the tooth around the tissue.

\section{CONCLUSIONS}

Tooth bleaching using the NAPP resulted in a better bleaching effect than the use of the PAC and diode laser with a $15 \%$ CP. In addition, the NAPP treatment did not increase the temperature of the tooth surface above $37^{\circ} \mathrm{C}$, indicating that the NAPP does not cause any thermal damage to the tooth. Therefore, the NAPP can be a useful tooth bleaching device that provides a high bleaching effect with a low concentration of HP. As such, it could replace conventional light sources that have limitations, such as questionable bleaching efficacy and high temperatures.

\section{ACKNOWLEDGEMENTS}

This research was supported by Basic Science Research Program through the National Research Foundation of Korea (NRF) funded by the Ministry of Education, Science and Technology (20100010322). 


\section{REFERENCES}

1- Berger SB, Coelho AS, Oliveira VA, Cavalli V, Giannini M. Enamel susceptibility to red wine staining after $35 \%$ hydrogen peroxide bleaching. J Appl Oral Sci. 2008;16:201-4.

2- Baik JW, Rueggeberg FA, Liewehr FR. Effect of light-enhanced bleaching on in vitro surface and intrapulpal temperature rise. J Esthet Restor Dent. 2001;13:370-8.

3- Buchalla W, Attin T. External bleaching therapy with activation by heat, light or laser - a systematic review. Dent Mater. 2007;23:586-96.

4- Dahl JE, Pallesen U. Tooth bleaching - a critical review of the biological aspects. Crit Rev Oral Biol Med. 2003;14:292-304.

5- Eldeniz AU, Usumez A, Usumez S, Ozturk N. Pulpal temperature rise during light-activated bleaching. J Biomed Mater Res B Appl Biomater. 2005;72:254-9.

6- Erikkson A, Albrektsson T, Grane B, McQueen D. Thermal injury to bone: a vital microscopic description of heat effects. Int J Oral Surg. 1982;11:115-21.

7- Fridman G, Friedman G, Gutsol A, Shekhter AB, Vasilets VN, Fridman A. Applied plasma medicine. Plasma Processes Polym. 2008;5:503-33.

8- Haywood VB. A comparison of at-home and in-office bleaching. Dent Today. 2000;19:44-53.

9- Hein DK, Ploeger BJ, Hartup JK, Wagstaff RS, Palmer TM, Hansen LD. In-office vital tooth bleaching - what do lights add? Compend Contin Educ Dent. 2003;24:340-52.

10- Iza F, Kim GJ, Lee SM, Lee JK, Walsh JL, Zhang YT, et al. Microplasmas: sources, particle kinetics, and biomedical applications. Plasma Processes Polym. 2008;5:322-44.

11- Joiner A. The bleaching of teeth: a review of the literature. J Dent. 2006;34:412-9.

12- Jones AH, Diaz-Arnold AM, Vargas MA, Cobb DS. Colorimetric assessment of laser and home bleaching techniques. J Esthet Dent. 1999;11:87-94.

13- Kang SK, Choi MY, Koo IG, Kim PY, Kim Y, Kim GJ, et al. Reactive hydroxyl radical-driven oral bacterial inactivation by radio frequency atmospheric plasma. Appl Phys Lett. 2011;98:143702. 14- Kashima-Tanaka M, Tsujimoto Y, Kawamoto K, Senda N, Ito K, Yamazaki M. Generation of free radicals and/or active oxygen by light or laser irradiation of hydrogen peroxide or sodium hypochlorite. J Endod. 2003;29:141-3.

$15-$ Kugel G. Is there a benefit to light-activated tooth whitening? J Can Dent Assoc. 2005;71:420-1.
16- Lee HW, Kim GJ, Kim JM, Park JK, Lee JK, Kim GC. Tooth bleaching with non-thermal atmospheric pressure plasma. J Endod. 2009;35:587-91.

17- Lee HW, Nam SH, Mohamed AAH, Kim GC, Lee JK. Atmospheric pressure plasma jet composed of three electrodes: application to tooth bleaching. Plasma Processes Polym. 2010;7:274-80.

18- Lim MY, Lum SO, Poh RS, Lee GP, Lim KC. An in vitro comparison of the bleaching efficacy of $35 \%$ carbamide peroxide with established intracoronal bleaching agents. Int Endod J. 2004;37:483-8.

19- Lima DA, Aguiar FH, Liporoni PC, Munin E, Ambrosano GM, Lovadino JR. In vitro evaluation of the effectiveness of bleaching agents activated by different light sources. J Prosthodont. 2009;18:249-54.

20- Lloyd G, Friedman G, Jafri S, Schultz G, Fridman A, Harding K. Gas plasma: medical uses and developments in wound care. Plasma Processes Polym. 2010;7:194-211.

21- Luk K, Tam L, Hubert M. Effect of light energy on peroxide tooth bleaching. J Am Dent Assoc. 2004;135:194-201.

22- Marson FC, Sensi LG, Vieira LC, Araújo E. Clinical evaluation of in-office dental bleaching treatments with and without the use of light-activation sources. Oper Dent. 2008;33:15-22.

23- Nakamura T, Saito O, Ko T, Maruyama T. The effects of polishing and bleaching on the colour of discoloured teeth in vivo. J Oral Rehab. 2001;28:1080-4.

24- Papathanasiou A, Kastali S, Perry RD, Kugel G. Clinical evaluation of a $35 \%$ hydrogen peroxide in-office whitening system. Compend Contin Educ Dent. 2002;23:335-8.

25- Park JK, Nam SH, Kwon HC, Mohamed AAH, Lee JK, Kim GC. Feasibility of non-thermal atmospheric pressure plasma for intracoronal bleaching. Int Endod J. 2011;44:170-5.

26- Peutzfeldt A, Sahafi A, Asmussen E. Characterization of composites polymerized with plasma arc curing units. Dent Mater. $2000 ; 16: 330-6$

27- Smigel I. Laser tooth whitening. Dent Today. 1996;15:32-6. 28- Sulieman M. An overview of tooth discoloration: extrinsic, intrinsic and internalized stains. Dent Update. 2005;32:463-4.

29- Villalta P, Lu H, Okte Z, Garcia-Godoy F, Powers JM. Effects of staining and bleaching on color change of dental composite resins. J Prosthet Dent. 2006;95:137-42.

30- Yazici AR, Khanbodaghi A, Kugel G. Effects of an in-office bleaching system (ZOOM) on pulp chamber temperature in vitro. J Contemp Dent Pract. 2007;8:19-26. 